\title{
O PERFUME DO MUNDO: CONSUMO DE EXPERIÊNCIAS DE MARCA PELO OLFATO
}

\author{
The perfume of the world: consumption of brand \\ experiences by the sense of smell \\ El perfume del mundo: consumo de experiencias de \\ marca por el olfato
}

\begin{abstract}
Guilherme Nery Atem
Universidade Federal Fluminense, Rio de Janeiro, Brasil.

Graduado em Comunicação Social/Publicidade pelas Faculdades Integradas Hélio Alonso. Especialista em Filosofia Contemporânea pela Pontifícia Universidade Católica do Rio de Janeiro. Mestre em Comunicação e Cultura pela Universidade Federal do Rio de Janeiro e em Letras/Linguística pela Universidade do Estado do Rio de Janeiro. Doutor em Comunicação e Cultura pela Universidade Federal do Rio de Janeiro e pós-doutor em Letras/Linguística pela Universidade do Estado do Rio de Janeiro. Professor do Departamento de Comunicação Social da Universidade Federal Fluminense.

E-mail: gui.nery@globo.com
\end{abstract}

\section{Fernanda Ferreira de Abreu}

Universidade Federal Fluminense, Rio de Janeiro, Brasil.

Graduada em Comunicação Social/Publicidade pela Universidade Federal Fluminense. Mestre em Ciência da Arte pela mesma instituição. Doutora em Antropologia Social pela Universidade Federal do Rio de Janeiro. Professora do Departamento de Comunicação Social da Universidade Federal Fluminense.

E-mail: feabreu82@hotmail.com

RESUMO Este trabalho enfoca a análise das relações entre consumo de experiências e o sentido humano do olfato. Nosso objetivo principal é mapear o que se tem produzido sobre tal relação a partir de diferentes recortes disciplinares. Só recentemente as ciências humanas e sociais, em geral, e o marketing e a publicidade, em particular, vêm se interessando pelo olfato. Daí trazermos esta discussão, com uma pesquisa de caráter exploratório, seguindo as principais formulações teóricas e complementando-a com exemplos de casos em pontos de venda, mais especificamente.

PALAVRAS-CHAVE Consumo de experiências, Olfato, Filosofia, Publicidade, Ponto de venda.

ABSTRACT This work focuses on the analysis of the relationship between consumption of experiences and the human sense of smell. Our main objective is to map what has been produced about this relationship from different disciplines. Only recently the human and social sciences, in general, and marketing and advertising, in particular, have been showing interest in smell. Hence we bring this discussion, with an exploratory research, following the major theoretical formulations and complementing it with case examples of points of purchase, more specifically.

KEYWORDS Consumption of experiences, Smell, Philosophy, Advertising, Point of purchase.



artigo 
RESUMEN El trabajo se centra en el análisis de las relaciones entre el consumo de experiencias y el sentido humano del olfato. Nuestro objetivo principal es mapear lo que se ha producido sobre tal relación a partir de diferentes recortes disciplinares. Sólo recientemente las ciencias humanas y sociales, en general, y el marketing y la publicidad, en particular, se interesan por el olfato. Desde ahí traemos esta discusión, con una investigación de carácter exploratorio, siguiendo las principales formulaciones teóricas y complementándolas con ejemplos de casos, más específicamente en puntos de venta. PALABRAS CLAVE Consumo de experiencias, Olfato, Filosofía, Publicidad, Punto de venta.

\section{INTRODUÇÃO}

Hoje vivemos em uma época de significativas transformações nas práticas de consumo. Desde o início da modernidade, o capitalismo de produção vem se pautando pelas exigências da cultura de consumo. $\mathrm{O}$ acirramento da concorrência na produção e venda de bens de consumo, junto de constantes novidades tecnológicas, gerou excesso de marcas e aceleração da circulação de bens (tangíveis) e de signos (intangíveis).

A cultura passa por um momento de estetização generalizada (LIPOVETSKY; SERROY, 2015), na qual o consumo de experiências dirige a própria experiência de viver o cotidiano. Não nos parece razoável o estabelecimento de exclusões ou alternativas teóricas entre "ideologias”, de um lado, e "experiências sensoriais ou semióticas", de outro (a "era sensológica” (PERNIOLA, 1993)). Parece-nos mais promissor pensarmos nas articulações entre essas dimensões, e nisto acompanhamos Bakhtin (1992).

Este texto busca pensar as relações entre os atuais modos de consumo de experiências e o sentido humano do olfato. O objetivo principal é o mapeamento do que tem sido produzido de conhecimento sobre tal relação a partir de diferentes recortes disciplinares: comunicação não verbal (HALL, 1977; DAVIS, 1979); marketing sensorial (LINDSTROM, 2012; PEREZ, 2016); branding emocional (GOBÉ, 2005); marketing olfativo (FARKAS, 2013); filosofia empirista (SOARES; MIRANDA, 2009; JAQUET, 2010) etc.

O olfato tem sido considerado, pela maioria das culturas e na maior parte do tempo, o sentido menos importante (ou nobre) do corpo humano. "O cheiro tem sido pouco estudado como possibilidade de identificação de uma marca, mas entender sua sensorialidade pode se configurar como diferencial na miríade de produtos à disposição dos consumidores" (PEREZ, 2016, p. 106). A despeito disso - e ao contrário -, o olfato começa a ser considerado em pesquisas mais recentes o sentido mais poderoso e envolvente (HALL, 1977; LINDSTROM, 2012). Só recentemente o marketing e a publicidade vêm se interessando pelo olfato (FARKAS, 2013; LAVAREDA; CASTRO, 2016).

Como se trata de uma incursão inicial nossa no tema proposto, daremos um viés ensaístico e não traremos, no momento, resultados de pesquisa, mas esperamos contribuir com o debate levantando questões pertinentes.

\section{O OLFATO NA FILOSOFIA}

Contemporaneamente, considera-se a subjetividade como um "contínuo de sensações, modos de existir, amar e comunicar, de imagens, sons, cheiros, afetos, valores e formas de consumo literalmente fabricadas 
no entrecruzamento de instâncias sociais, técnicas, institucionais e individuais...” (Soares; Miranda, 2009, p. 415). Subjetividade, assim, é "tudo aquilo que concorre para a produção de um 'si', um modo de existir, um estilo de existência” (Ibidem, p. 416). A experiência estética nos arranca do exílio interior e nos lança na empiria das percepções e afeç̧ões.

A filosofia sempre valorizou o sentido da visão, principalmente, mas também a audição. Paladar, tato e olfato tradicionalmente foram bem menos evidenciados. A “anosmia dos filósofos” (Jaquet, 2010, p. 5) refere-se exatamente à falta de capacidade de perceber filosoficamente os cheiros e de, portanto, pensá-los. "O perfume é mais capaz de captar a atenção dos sofistas do que dos filósofos” (Ibidem, p. 11).

As raras exceções em filosofia na verdade não se dedicaram ao olfato, mas quando muito o mencionaram rápida e superficialmente. Buscando preencher essa lacuna, Chantal Jaquet (Ibidem) afirma que o odor tem potência suficiente para fornecer certos modelos de pensamento para a construção do conhecimento. Para a autora, não se trata apenas de a filosofia pensar no olfato como objeto de investigação, mas de se constituir uma "filosofia do nariz", em que o olfato forneceria seus parâmetros para o conhecimento (como a visão, tradicionalmente).

O que pensamos ser uma inferioridade natural do olfato não passa de inferioridade cultural. Em Pinóquio o nariz é traidor, revela o que gostaríamos de esconder. O cheiro nos lembra de nossa animalidade, mas não se reduz a isto. Os modos mesmos de experimentação e interpretação dos odores são marcados por diferenças culturais, sociais e até econômicas.

$\mathrm{Na}$ Antiguidade os filósofos em geral, com sua anosmia, praticamente ignoraram o olfato. Demócrito, que estudou os cheiros e o olfato como combinações de átomos específicos, estabeleceu uma analogia entre a alma e o perfume. Heráclito, com seu mobilismo, disse que "se todas as coisas se tornassem fumaça, nós as conheceríamos pelas narinas” (Ibidem, p. 334-335). Mas não foram muito além.

É em Empédocles que encontramos as melhores condições para o desenvolvimento de um "pensamento nasal". O filósofo concilia os sentidos do corpo com a razão; a filosofia entre o nariz e a alma. Ele deu atenção particular ao cheiro: fala-se de sua panosmia filosófica. Empédocles denunciava a hegemonia da visão e da audição. Propunha seu ultrapassamento e a retomada de um equilíbrio entre os cinco sentidos. A sensação resulta de uma harmonia entre os objetos percebidos e os poros que os percebem. Haveria, para ele, uma semelhança entre emissor e receptor.

Platão teria sido muito reticente e impreciso quanto ao olfato. Diferenciou "prazeres puros e verdadeiros" (só prazer e sempre; aqueles que vêm do mundo ideal) e "prazeres impuros e misturados" (prazer e dor; que vêm do mundo sensível). O odor é um prazer impuro e misturado, embora toque o mundo ideal (menos divino que a visão e a audição). O status ontológico do odor, em Platão, é problemático. "O odor se vê dotado de um estatuto intermediário entre o ser e o devir” (Ibidem, p. 253). Já Aristóteles positivou o olfato: este só se reduz à função vital de proteção e conservação da vida nos animais. No homem, emancipando-se do paladar é que o olfato se abrirá à fruição estética desinteressada. Daí pode haver uma "estética do olfato".

Na modernidade, contudo, Kant negativou olfato: o olfato seria antissocial e involuntário, justamente por ser impositivo, autoritário, tirânico. Ao inspirarmos o ar, sentimos um cheiro, este nos penetra fundo e atinge nossos pulmões, sem chance de recusa. O cheiro seria sempre de "mau gosto". A cidade ideal seria inodora. 
Hobbes relativiza o olfato: o mesmo cheiro é considerado bom ou ruim, dependendo de quem o exala. Se o cheiro vier de mim mesmo, será bom/agradável. Se vier de outrem, será ruim/desagradável. Um cheiro de outrem é como uma ameaça velada, baseada na experiência passada (lembremo-nos de seu "estado de natureza"). E é preciso proteger-se desse “outrem”. Ele mostra que a percepção do odor é sintomática da relação (afetiva e representacional) que um sujeito tem com o mundo.

Uma bela leitura filosófica da arte, na contemporaneidade, foi feita por um artista japonês que mora na Suécia. Hiroshi Koyama criou uma exposição - "Reconhecimento do incenso" - que juntava uma pedra negra (diábase), extraída de uma camada muito funda da Terra, com incensos. A pedra parecia exalar o odor do incenso. Os cheiros eram mais do que decorativos ou acessórios; compunham com a rocha uma unidade de sentido - os contrários: solidez, resistência, fixidez e necessidade cega da matéria da pedra em agenciamento com volatilidade, fluidez, mobilidade e liberdade do cheiro. Uma coisa aponta para a eternidade, a outra para a fugacidade. $\mathrm{O}$ artista uniu criativamente o espírito e o nariz, e assim criou uma estética olfativa de fato.

O olfato nos joga na presença do mundo. São puras evidências ou dados imediatos. Os perfumes encarnam um modelo da verdade pensada sob o modo da presença, e não da representação (JAQUET, 2010, p. 315). Filosofias materialistas e empiristas/sensualistas são bastante propensas a buscar esse tipo de "conhecimento nasal". Pelo nariz nós respiramos a inteligência, e a verdade nos é insuflada (Ibidem, p. 338).

\section{O OLFATO NA COMUNICAÇÃo NÃO VERBAL}

O nariz e o olfato aparecem mais e melhor na história cultural, na literatura e na antropologia do que na filosofia. De um ponto de vista não etnocêntrico o olfato é, sim, um sentido extremamente social (em uma explícita crítica a Kant). Há muitas formas e regras de sociabilidade por meio dos odores. Muitas culturas não ocidentais valorizam o olfato. Os Desana, da Amazônia colombiana, por exemplo, têm um sistema complexo de relações conjugais baseado nas diferenças de cheiros de cada família. Casar-se, para eles, é saber combinar cheiros (Ibidem). E há os interditos olfativos (sociais), claro.

Pesquisas de Albert Scheflen e Ray Birdwhistell, com base na etologia de Irenäus Eibl-Eibesfeldt e de Adam Kendon, buscaram as formas de "galanteio" na natureza que se reproduziriam, com sofisticações, na cultura humana: olhares; cheiro do corpo (feromônios); gestos etc. (DAVIS, 1979). O homem também se comunica pelo olfato, pelo tato e pelo paladar - para além da visão e da audição. Esses sentidos fazem parte de uma mensagem global, o que deságua na multissensorialidade publicitária, da qual falaremos adiante.

Somos uma sociedade bastante desodorizada. Vivemos com medo do mau hálito, do cheiro do suor, do cheiro da genitália ou das axilas etc. Buscamos substituir os odores naturais pelos industrializados. O olfato, como a audição, não tem interrupção duradoura. Os árabes e os balineses admitem mais uma relação entre o cheiro de alguém e a nossa disposição para com essa pessoa. Na Nova Guiné Meridional, o amigo que fica toca a axila daquele que irá partir, para guardar consigo o cheiro daquele que irá viajar (HALL, 1977).

Nos animais, o olfato serve para buscar alimentos ou parceiros sexuais, para alertar da presença de predadores, para demarcar território, 
para reencontrar seu rebanho, para identificar o estado emocional de outras espécies. O salmão usa seu olfato para a desova. Já o homem aprendeu a confiar mais na visão do que no olfato. Segundo o dr. Harry Wiener (DAVIS, 1979), nós percebemos odores que não registramos conscientemente. Haveria, então, um “inconsciente olfativo".

É Flora Davis (Ibidem) quem nos traz um resumo de diferentes modos de organização cognitiva e social pelo olfato. Cada indivíduo teria uma "assinatura olfativa”, e os cães sabem disso. Os mosquitos sentem cheiros diferentes de cada pessoa e se sentem atraídos diferentemente por elas. Esquizofrênicos exalariam um cheiro característico, que ratos perceberiam.

As pessoas não costumam falar sobre cheiros. Talvez subestimemos a importância cultural do olfato por ser algo um tanto assustador. O "tabu do olfato", se assim podemos dizer, atravessou diferentes culturas, em diferentes tempos e lugares. Entretanto a cultura contemporânea parece ter começado a reconhecê-lo e valorizá-lo - claro, não sem antes torná-lo fonte de lucro e exploração mercadológica.

\section{MULTISSENSORIALIDADE E OLFATO}

O contexto atual já é de uma "nova economia da atenção" - "papel desempenhado pela atenção na dinâmica cognitiva sob os impactos da alta velocidade, sobrecarga de estímulos e de informação, fragmentação do tempo nas novas formas de vida social cibercentrada" (SANTAELLA, 2010, p. 303) - e, em função disso, a publicidade busca novos caminhos para a obtenção de relevância, interatividade e experiência (ATEM; OLIVEIRA; AZEVEDO, 2014).

Essas possibilidades não abarcam necessariamente as mediações e tecnologias digitais. Nota-se uma tentativa de se aproximar dos públicos consumidores, obtendo não apenas sua atenção, como também seu envolvimento emocional por meio de experiências sinestésicas, a exemplo do que se tem denominado, desde 2013, de live marketing.

Segundo Coelho (2015), live marketing seria uma evolução do marketing promocional e abarcaria, sobretudo, eventos, promoção de vendas e merchandising no ponto de venda ${ }^{1}$. No site da Revista Live Marketing - iniciativa da Associação de Marketing Promocional (Ampro) para promover o novo conceito - há exemplos, pouco detalhados, de ações de comunicação que exploram a multissensorialidade, tal como a segunda edição da Campari Red Experience no Nordeste (em setembro de 2017), que contou com instalações sensoriais/obras interativas no Centro Dragão do Mar de Arte e Cultura, em Fortaleza, as quais buscavam explorar todos os cinco sentidos, tendo como inspiração a bebida que tem um sabor bittersweet e procura transmitir sofisticação, sensualidade, tradição e ousadia (CAMPARI..., 2017). Entretanto o que foi feito para explorar cada um dos sentidos não é explicitado na matéria, muito menos os resultados da ação.

De fato, é difícil encontrar dados que mostrem não só os resultados globais da ação, mas especialmente a contribuição de cada um dos sentidos. O projeto Brand Sense, liderado por Martin Lindstrom (2012) e iniciado em 1999, buscou justamente suprir essa lacuna investigando o papel de cada um dos cinco sentidos na construção de laços afetivos entre consumidores e marcas em 24 países e com a participação de 600 pesquisadores.

1. Questionamos a validade da nomenclatura live marketing e sua tentativa de se opor à publicidade tradicional em outro artigo (cf. ABREU, 2018). 
Lindstrom (Ibidem, p. 5) é enfático ao afirmar que, no atual contexto, 'se quiserem sobreviver, as marcas terão de incorporar uma 'plataforma' de marca (significando um conjunto de associações que um consumidor faz com um produto ou empresa) que una os cinco sentidos por completo". É fornecido o exemplo da Singapore Airlines como marca sensorial por esta construir um diálogo multissensorial com seus consumidores: o logo da marca nos pratos; manual detalhado de como atender; uniformes da Singapore Girl feitos sob encomenda; anúncios do comandante redigidos por agência de publicidade; aroma especificamente projetado, utilizado pelas comissárias de bordo e acrescentado às toalhas quentes servidas antes da decolagem etc.

Se por um lado a visão é o sentido privilegiado nas culturas ocidentais modernas, por outro somos sobrecarregados de estímulos visuais. $\mathrm{Na}$ obra A lógica do consumo - na qual se debruça sobre as descobertas feitas com a metodologia do neuromarketing, que objetiva acessar as ondas cerebrais para melhor entender as forças não conscientes que motivam nossos comportamentos de consumo -, Lindstrom (2016, p. 125) destaca que:

as imagens visuais são muito mais eficazes e memoráveis quando estão associadas a outro sentido - como a audição e o olfato. As empresas estão descobrindo que, para nos cativar emocionalmente de forma plena, seria melhor não apenas nos inundar de logomarcas, mas também borrifar fragrâncias em nossas narinas e encher nossos ouvidos de música.

$\mathrm{O}$ autor constatou, inclusive, que o apelo multissensorial ativa um vínculo mais forte com a marca e afeta positivamente a percepção da qualidade do produto, permitindo aumentar seu preço. Para tanto, foi realizado o seguinte experimento: dois pares idênticos de tênis da marca Nike foram colocados em duas salas separadas, porém idênticas visualmente, com a diferença de que uma delas havia sido borrifada com um cheiro floral misto, e a outra não. Após inspecionarem os calçados, os sujeitos que se submeteram ao experimento responderam a um questionário que indicou a preferência, por uma margem de 84\%, pelos tênis na sala com fragrância. Além disso, esses consumidores estimaram que o preço dos tênis da sala perfumada era, aproximadamente, $\$ 10,33$ mais alto do que o par da sala sem fragrância (Idem, 2012, p. 103).

Sem perder de vista a importância da integração entre os sentidos, optamos por focar no olfato no presente artigo, considerando o que autores de diferentes áreas destacam a respeito de sua potência, conforme vimos acima. Devemos ainda sinalizar que, nas publicações acadêmicas no âmbito do marketing e da publicidade, o olfato também vem ganhando importância.

De acordo com Gobé (2005, p. 103, tradução nossa), “o olfato é o sentido mais forte. [...] cheiros podem evocar nossas emoções de forma mais potente do que qualquer outro sentido". Lavareda e Castro (2016, p. 149) se referem ao olfato como "o agente avançado das emoções" e ressaltam que "é o único dos sentidos que se conecta diretamente com o sistema límbico e muito intimamente com o hipocampo, que é o mais importante centro da memória”. Perez (2016, p. 105) destaca que o aroma é instintivo e involuntário, não sendo filtrado pelo cérebro, e também enfatiza que o cheiro traz permanência e memória. Lindstrom (2016, p. 129), por sua vez, salienta que o olfato é o mais arraigado de todos os sentidos e também aborda a existência de uma linha direta dos odores até o sistema límbico, responsável pelo controle das emoções, lembranças e sensação de bem-estar. 
Outro motivo para selecionamos o olfato foi o fato de este ainda ser pouco utilizado para estimular o consumo de bens, serviços e experiências, apesar de ser considerado, em pesquisas recentes - a exemplo da realizada por Lindstrom (2012) -, como o mais poderoso e envolvente dos sentidos. Não obstante haver exemplos pontuais de utilização do olfato em anúncios veiculados nas mídias ditas tradicionais, como jornal, revista, mídia exterior e cinema, parece-nos que o seu futuro está no ponto de venda.

Isso se deve possivelmente ao fato de que é mais difícil controlar a potência e a propagação do aroma, bem como a segmentação do público, no espaço aberto em que se localizam os formatos de mídia exterior. No caso de anúncios de cinema, o aroma pode deixar rastros para os anúncios seguintes e para o próprio filme a que as pessoas foram assistir. O mesmo pode ser dito em relação aos anúncios em mídia impressa com aromas, capazes de contaminar todo o jornal ou a revista.

Ao sinalizar que experiências com fragrâncias também podem dar errado, Lindstrom (2016, p. 132) menciona o caso da campanha "Got milk?”, realizada em São Francisco. Anúncios em pontos de ônibus precisaram ser recolhidos quando passageiros reclamaram que os aromas de chocolate e massa de biscoito estavam desencadeando reações alérgicas. Num ambiente fechado os efeitos não poderiam ser ainda piores? Contudo, quando se trata de ponto de venda, já há certa expectativa por determinados aromas, especialmente em ambientes que comercializam alimentos e cosméticos.

Talvez por isso os profissionais de live marketing reclamem para si a capacidade de proporcionar uma experiência de marca por meio dos cinco sentidos. A eliminação das mídias ou veículos de comunicação utilizados pela publicidade tradicional - parece favorecer o apelo multissensorial. Farkas ressalta, assim, "o fato de que o aroma ambiental é o próprio veículo (ou mídia) que impulsiona a venda dos produtos” (2013, p. 83).

Escapa ao presente escopo discutirmos as supostas diferenças entre live marketing e publicidade tradicional. Todavia, consideramos importante pontuar que a própria publicidade tradicional vem sofrendo transformações para proporcionar cada vez mais relevância, interatividade e experiência (ATEM; OLIVEIRA; AZEVEDO, 2014), conforme já sinalizado. Dessa forma, em vez de enfatizar diferenças entre modalidades comunicacionais, preferimos acompanhar Perez (2016) e pensar em um ecossistema publicitário.

Nesse ecossistema o poder do visual e também do audiovisual parece se dissipar à medida que os consumidores são cada vez mais expostos a imagens e vídeos. Lindstrom (2016, p. 142) vislumbra, assim, o seguinte cenário:

Finja que estamos em 2030. Estamos naquele mesmo "cruzamento do mundo", Times Square. Mas, em vez de outdoors e letreiros piscantes, levantamos nossa cabeça para ver... nada. Nenhum modelo de sete metros de altura. Nenhum néon brilhante. Ao mesmo tempo, a calçada está repleta de cheiros e sons. Uma lufada de limão sai de uma loja que vende um novo tênis que você não pode deixar de ter. Uma rajada de laranja madura sai de uma grande loja de artigos esportivos. Um perfume pegajoso sai das portas de um hotel recém-inaugurado. [...] O que estou descrevendo é um sutil ataque sensorial que não se baseia exclusivamente na visão, mas que atiça nossas narinas, ouvidos e as pontas de nossos dedos. 
Pelo nosso levantamento, ainda que inicial, pudemos constatar que o olfato é realmente pouco explorado. Mas as ações - ainda escassas, tendo em vista todo o seu potencial - parecem mesmo se concentrar e apresentar tendência de crescimento nos pontos de venda ou varejistas, conforme também salientam outros autores além de Lindstrom.

\section{O OLFATO NO PONTO DE VENDA}

O único livro específico de marketing olfativo que encontramos no Brasil foi o de Farkas (2013). Ainda que o título da obra seja marketing olfativo, seu foco nem é propriamente em marketing e comunicação. Como indicado no subtítulo, trata-se de um "guia para aromatização de ambientes”, com ênfase em aromaterapia e nas propriedades e potencialidades das mais diversas essências. No breve trecho em que trata de marketing olfativo consta que ele pode desempenhar as seguintes funções:

- Identificar a marca, distinguindo-a das outras.

- Aumentar fortemente o apelo de vendas no ponto de venda ou diminuir a rejeição de produtos.

- Gerar sensações que melhorem as relações humanas no ambiente de trabalho.

- Transmitir ao cliente um cuidado especial com ele durante sua permanência no espaço de interação.

- Possibilitar às empresas, principalmente as de varejo e hotelaria, a criação de linhas de produtos a partir de seu aroma.

- Ajudar a regular emocionalmente as relações entre o cliente e o negócio, particularmente no varejo, em que pode, por exemplo, aumentar ou diminuir o desejo de permanência do cliente no espaço de vendas e outros efeitos. (FARKAS, 2013, p. 80)

Percebe-se a ênfase no ponto de venda e no varejo, o que se relaciona também ao aroma dos próprios produtos. É destacado, desse modo, que "a aromatização do produto é fundamental no momento decisivo da compra na gôndola do supermercado" (Ibidem, p. 81). Perez (2016, p. 105) menciona, por exemplo, que o cheiro pode funcionar como um índice da maciez (não passível de verificação no momento da compra) no caso de amaciantes de roupa.

Os aromas atuam, assim, como signos distintivos de produtos e lojas. "A intenção principal é traduzir o espírito da marca, sempre tendo em vista o público-alvo" (FARKAS, 2013, p. 84), o que pode ser reforçado ao se sinalizar o surgimento no mercado do conceito de "logo olfativo" (VALENTIM, 2007). A respeito do público-alvo, Farkas indica que idades diferentes exigem aromas diferentes, e que o mesmo pode ser dito em relação ao sexo. O gerânio, por exemplo, é classificado como "o melhor amigo da mulher” (FARKAS, 2013, p. 113). Já Gobé (2005, p. 105) indica que as lojas de móveis Jordan's, de Massachusetts, usam aroma de chiclete no departamento infantil e aroma de pinho na seção de móveis rústicos.

Futuramente pretendemos investigar a cientificidade dessas classificações e até que ponto não reforçam estereótipos. Por ora, apresentaremos mais exemplos de aplicação do olfato em pontos de venda. Ruy Hirschheimer, presidente da Electrolux, enfatiza que, por meio do aroma, é possível "reforçar a sofisticação e inovação presentes em nossos produtos e o conforto da nossa loja premium" (FARKAS, 2013, p. 90). 
O olfato é trabalhado na loja conceito (flagship store) da marca. Lojas conceito teriam por foco a construção da imagem da marca por meio de experiências, e não propriamente a comercialização de produtos, ainda que este seja o objetivo final.

Outro depoimento colhido por Farkas foi o de Renata Feffer, proprietária da Cau Chocolates, que possui lojas em São Paulo. Conta a empresária:

Decidimos fazer a aromatização porque a loja se encontra em um shopping, que tem um aroma "impessoal”. O projeto de aromatização contribuiu para enriquecer a experiência que o cliente/consumidor tem quando entra nela. Selecionamos um aroma que remete ao chocolate, mas que não tem cheiro de chocolate. (FARKAS, 2013, p. 91-92)

Nesse caso, não é feita referência a uma loja conceito, mas também ganha destaque o enriquecimento da experiência. Cabe sinalizar que Higo Lopes, gerente de visual merchandising dos cosméticos Granado, explica - em entrevista a Machado (2016, p. 36) - que todas as suas lojas são lojas conceito, já que têm como objetivo criar uma experiência de marca o mais sensorial possível, de forma a gerar uma memória afetiva de longo prazo a ser acionada no contato com a marca nas redes varejistas, como supermercados e farmácias.

Para complementar nosso levantamento inicial, procuramos consultar renomados veículos do mercado publicitário, como Adnews, Meio \& Mensagem e propmark, pesquisando por matérias que contivessem as palavras, olfato, olfativo(a) e cheiro. Entre as ações que teriam utilizado o olfato no último ano (ou seja, de 2017 ao início de 2018), encontramos quatro em mídia exterior (abrigo de ônibus/mobiliário urbano e metrô) e apenas uma em ponto de venda, o que pode também se dever ao fato de que a publicidade olfativa em mídia exterior ainda é considerada uma novidade, adquirindo mais atratividade como notícia do que as mais habituais ações de marketing olfativo em ponto de venda.

A ação em ponto de venda encontrada refere-se justamente a uma loja conceito da Klin, marca de calçados infantis. Sua primeira loja desse tipo foi criada em São Paulo, em setembro de 2017, com o objetivo de tangibilizar o conceito "criançar", exaltando que o mais importante é ser criança e brincar.

Os sentidos olfato, paladar, toque, visão e audição são explorados no ambiente. A loja da fabricante de calçados infantis tem um aroma criado para ela; carrega as cores da marca, com destaque para o amarelo; oferece formas arredondadas e texturas especiais; disponibiliza joguinhos, a possibilidade de brincar com os calçados. O cachorro Klin, ícone da marca, também está no espaço. (LOJA-CONCEITO..., 2017)

No cenário futuro vislumbrado por Lindstrom (2016), parece que todos os pontos de venda serão lojas conceito, à medida que as marcas forem descobrindo o potencial das experiências sensoriais, com destaque para o olfato. Gobé (2005, p. 105, tradução nossa) salienta, assim, que "fragrâncias bem planejadas aumentam as vendas [...] clientes permanecem por mais tempo nas lojas de departamento que cheiram bem, em comparação com zonas não perfumadas”.

Regina Blessa (2015, p. 35), autora referência em merchandising em ponto de venda no Brasil, ressalta que "cheiros apetitosos como o do 
forno da padaria, o da pizzaria, [...] reforçam a vontade e o apetite, que podem ser notados quando os consumidores esperam pelos produtos, que ainda nem saíram, em longas filas sem qualquer reclamação”. Provavelmente a eficácia será ainda maior se os alimentos também tiverem um visual atraente. A associação entre a visão e o olfato atuará na estimulação do paladar.

Como reforça Lindstrom (2016, p. 143), a "estrada para a emoção passa por nossas experiências sensoriais”; e as escolhas de compras costumam ser guiadas pela emoção, mais do que pela razão (GOBÉ, 2005).

\section{CONSIDERAÇÕES FINAIS}

A partir do que foi exposto, o futuro do marketing olfativo ou do consumo de experiências de marca pelo olfato parece estar no ponto de venda. Mas, à medida que todas as marcas passarem a proporcionar experiências multissensoriais, o que será preciso fazer para se destacar diante de uma concorrência acirrada? Teremos que acompanhar.

Um ponto que não podemos deixar de registrar e objetivamos desenvolver futuramente são as questões éticas envolvidas nesse "ataque sensorial", que seriam ainda mais sérias em função da "sutileza" mencionada por Lindstrom (2016, p. 142). A publicidade deixa de parecer publicidade - o que implica a transformação da publicidade denominada tradicional - para conquistar mais atenção e envolvimento emocional, por meio de relevância, interatividade e experiência (ATEM; OLIVEIRA; AZEVEDO, 2014).

Nesse processo, as defesas dos consumidores diminuem, especialmente no caso do olfato - que, conforme vimos, parece ser o caminho mais direto para o coração e para a memória. Por isso pensamos que, se Kant se equivocara ao afirmar ser o olfato desprovido de sociabilidade, ao menos é digna de relevância a crítica que faz ao seu caráter autoritário e inescapável (posto ser inseparável da respiração).

Estas questões que aqui propomos pretendem contribuir para uma reflexão coletiva mais ampla e aprofundada no tocante ao uso mercadológico do sentido do olfato. Percebemos como este é poderoso e envolvente em sua relação com os outros sentidos do corpo ativados na comunicação multissensorial. Daí a necessidade de abordá-lo interdisciplinarmente.

\section{REFERÊNCIAS}

ABREU, F. F. Live marketing existe? Reflexões sobre imbricamentos e tensões com a publicidade. Signos do Consumo, São Paulo, v. 10, n. 1, p. 4-14, 2018.

ATEM, G.; OLIVEIRA, T.; AZEVEDO, S. (Orgs.). Ciberpublicidade: discurso, experiência e consumo na cultura transmidiática. Rio de Janeiro: E-Papers; Faperj, 2014.

BAKHTIN, M. Marxismo e filosofia da linguagem: problemas fundamentais do método sociológico na ciência da linguagem. São Paulo: Hucitec, 1992.

BLESSA, R. Merchandising no ponto-de-venda. 4. ed. São Paulo: Atlas, 2015.

CAMPARI apresenta $2^{a}$ edição da Campari Red Experience no Nordeste. Revista Live Marketing, São Paulo, 29 ago. 2017. Disponível em: <https://bit.ly/2rgwiLB>. Acesso em: 7 abr. 2018.

COELHO, T. Do marketing promocional ao live marketing. São Caetano do Sul: Abccom, 2015.

DAVIS, F. A comunicação não-verbal. São Paulo: Summus, 1979.

FARKAS, F. L. Marketing olfativo: guia para aromatização de ambientes. São Paulo: Senac, 2013. 
GOBÉ, M. Fragrancias que seducen. In: Branding emocional. Barcelona: Divine Egg Publicaciones, 2005. p. 103-107.

HALL, E. A dimensão oculta. Rio de Janeiro: Francisco Alves, 1977.

JAQUET, C. Philosophie de l'odorat. Paris: Presses Universitaires de France, 2010.

LAVAREDA, A.; CASTRO J. P. Neuropropaganda de A a Z: o que um publicitário não pode desconhecer. Rio de Janeiro: Record, 2016.

LINDSTROM, M. Brandsense: segredos sensoriais por trás das coisas que compramos. Porto Alegre: Bookman, 2012.

A lógica do consumo: verdades e mentiras sobre por que compramos. Rio de Janeiro: HarperCollins Brasil, 2016.

LIPOVETSKY, G.; SERROY, J. A estetização do mundo: viver na era do capitalismo artista. São Paulo: Companhia das Letras, 2015.

LOJA-CONCEITO da Klin no Brasil aposta em "criançar". propmark, São Paulo, 10 out. 2017. Disponível em: <https://bit.ly/2rgU89k>. Acesso em: 27 abr. 2018.

MACHADO, K. Marketing sensorial no ponto de venda. 2016. 42 f. Monografia (Graduação em Comunicação Social) - Universidade Federal Fluminense, Niterói, 2016.

PEREZ, C. Signos da marca: expressividade e sensorialidade. 2. ed. São Paulo: Cengage Learning, 2016.

PERNIOLA, M. Do sentir. Lisboa: Editorial Presença, 1993.

SANTAELLA, L. A ecologia pluralista da comunicação: conectividade, mobilidade ubiquidade. São Paulo: Paulus, 2010

SOARES, L.; MIRANDA, L. Produzir subjetividades: o que significa? Estudos e pesquisas em Psicologia, Rio de Janeiro, ano 9, n. 2, p. 408-424, 2009. Disponível em: <https://bit. |y/2yK3m4|>. Acesso em: 27 jun. 2018.

VALENTIM, R. Afinal, o que é marketing olfativo? Portal do Marketing, São Paulo, 16 out. 2007. Disponível em: <https://bit.ly/2rgi2So>. Acesso em: 20 abr. 2018. 